\title{
Active and Traditional Teaching of Mathematics in Special Education
}

\author{
Saied Bishara \\ Special Education Department, Beit Berl College and Open University, Ra'anana, Israel \\ Email: saiedbs@gmail.com
}

Received 23 October 2015; accepted 19 December 2015; published 22 December 2015

Copyright (C) 2015 by author and Scientific Research Publishing Inc.

This work is licensed under the Creative Commons Attribution International License (CC BY). http://creativecommons.org/licenses/by/4.0/

(c) (i) Open Access

\section{Abstract}

This research project examines the differences between two teaching methods in the teaching of mathematics-active teaching and traditional teaching-in special education classes in standard elementary schools in the Arab sector of Israel. The differences examined are related to the advancement of scholastic achievements in mathematics, both from the aspect of understanding the study materials and the ability to solve mathematical problems. In addition, the impact of gender on achievements in mathematics in special education is also examined. This research project involved the participation of 40 students from four special education classes (Grades 3 and 4) at a standard elementary school. Two classes studied mathematics using the active teaching method, while the other two classes studied mathematics using the traditional teaching method. Findings indicated that among students who studied under the active teaching method, the improvement that occurred in the scope of mathematics achievements was distinctly greater than the improvement in scope of mathematics achievements occurring among students studying under the traditional teaching method. It was also found that among girls, the improvement occurring in the scope of mathematics achievements was distinctly greater than the improvement among boys. The characterizing of a teaching method that places an emphasis on active teaching may constitute a factor assisting in the boosting of scholastic achievements in mathematics, and its implications may also have impact on the teaching of other subjects. Active teaching may lead to the prevention of student drop-out from the educational framework, as well as fostering and motivating study and an improvement in social relationships.

\section{Keywords}

Teaching Methods, Active Teaching, Traditional Teaching, Mathematics Teaching, Special Education Classes, Special Education System 


\section{Introduction}

This research project examines the differences between two teaching methods-active and traditional—in the teaching of mathematics in special education classes at standard elementary schools in the Arab sector of Israel. Both methods strive to boost scholastic achievements in mathematics, from the aspects of understanding study materials and the ability to solve problems. It should be noted that the active teaching method suggests a new path in teaching - a path with which one can encourage and assist students experiencing difficulties and also facilitate in the perception of study materials.

Mathematics is considered to be one of the more difficult subjects studied in school—perhaps even the most difficult —as students are required to solve verbal problems, cope with research assignments, present situations using illustrations and mathematical representations, understand the properties of concepts and the relationships between them, and more. Thus, the student must possess strong abilities in logical thinking. Active teaching stresses social relationships among study participants in a school environment, as well as student actions in accordance with his/her personal study advancement, development of a flexible study program that corresponds to student needs, development and organization of diverse study materials and the use of alternatives in teaching. All these should serve as factors assisting in teaching math and in simplifying study materials for students with difficulties. The research objective was to examine the measure of change that should occur in the math student using the active teaching method, according to the RTI model (Response to Intervention) (Eylon \& Linn, 1988; Fischbein, 1997).

In order to examine the effect of teaching methods on scholastic achievements, this research project evaluated four special education classes studying within the standard elementary education framework-two classes studied mathematics according to the active teaching approach, and the other two according to the traditional teaching approach. The research hypothesis was that differences would be detected in scholastic achievement due to the differences in teaching methods.

Due to the lack of information on the unique characteristics of teaching methods and the relationship between them and the boosting of scholastic achievements in mathematics in special education, the present research engaged in the definition of these teaching approaches and examined the measure of impact of the various teaching methods on scholastic achievements in mathematics among students in special education. The definition of differences between the characteristics of active and traditional teaching approaches may enable a better understanding of the link between institutional components and scholastic achievement, and a more efficient design of the educational system.

\section{What Is Active Teaching?}

The basic premise of the active teaching method is that every study group in the class is heterogeneous, even if it would seem that the class or study group is composed on some homogenous basis. Moreover, as people learn from within various systems of social relationships, the structure of the social group and the dynamics within it will affect both individual and group learning. Therefore, differences among students and the heterogeneous composition of the study group constitute a starting point in the active teaching approach (Yisraeli, 2008).

The active teaching approach commenced in Israel in the 1960's in a small number of schools. The number of active schools gradually increased, and in 1976 the Ministry of Education established the Unit for Active Study. The active teaching approach does not draft preliminary definitions, but rather attempts to utilize local adaptation in the characterization of students and in the determination of objectives and directions for action in study, in knowledge and in study environments.

Globman and Harrison drafted a comprehensive definition for the active teaching approach in five detailed areas: a) the emphasis of warm interpersonal relationships among participants in the school environment; b) the emphasis of student action in independent guidance of his/her study; c) the development of a flexible study program that is adapted to its students; d) the development and organization of diverse materials and resources in the study environment that will trigger inquisitiveness and learning; e) the use of teaching methods and a range of social systems to develop diverse learning experiences (Kashti, Arieli, \& Shlaski, 1997).

Some combinations from within these five areas result in different implementation models for active teaching in schools. It should be noted that all five areas are implemented in every one of the models for active teaching; however, the differences lie in the measure of emphasis granted to each of the areas - an emphasis that endows each model with its own uniqueness (Kashti et al., 1997). 
One model, the individual-academic model, stresses humanity and socialness, placing the student at the center of scholastic processes and an advanced teaching program. This model attempts to address the differences among students according to level of achievements and learning style. Another model, the open corridor model, places more of an emphasis on the third and fourth areas of active teaching - an advanced teaching program and operation of an advanced study environment, and less on other areas of active teaching. According to this model, the environment responds to the differences in student interests and attempts to develop them from both a cognitive and expressive aspect simultaneously. A different model, the open school model, stresses the fifth area more, and flexibility becomes a basic principle in the operation of an educational environment. With this model, there is an attempt to refer not only to the different individual character traits among students, but also to the cultural differences among them (Globman \& Harrison, 1994; Kashti et al., 1997). Success in active teaching is dependent upon the measure of cooperation among all active elements in the school, from a belief that this method will assist the study population and provide a unique response to each individual student, in accordance with his/her personal abilities.

A few examples of the active teaching approach include small group instruction, peer assisted teaching, using computer games, digital presentation and briefs (Yisraeli, 2008).

In contrast, the traditional method refers to all study groups in a homogenous manner, where the teacher is at the center of the study process teaching all students in the same manner, in other words, without considering their individual differences with no pertinence to the differences among them. The structure of the curriculum is rigid, and is imposed upon the students from above; the use of illustrative means in teaching is minimal, which makes it difficult for students to understand the study materials, particularly those among them who experience learning difficulties. Furthermore, the student in traditional method of teaching is passively receiving information. The characteristics of the method is frontal, students receive information unilaterally and without using means of concrete and creative illustration, change of class location for group activity or any reciprocal type acticity (Kashti et al., 1997; Yisraeli, 2008).

In social sciences, there is a reference to the distinction between genders in teaching and learning. The characteristics of the active teaching approach, which emphasize humanity and socialness and focus on the student being at the center, while developing a teaching program suited to his/her needs, may contribute to the boosting of both genders equally and in decreasing gender gaps (Klein, 2008).

\section{Teaching in Special Education}

Special education is given to students with deficiencies that impact their functioning in a significant way. The education is designed to respond to the special needs of each student. A student is in need of special education when he cannot benefit from the standard kindergarten and school curriculum because they are not a fit to his way of learning and satisfy her needs (Bishara, 2005; Heiman \& Olenik-Shemesh, 2004).

One of the problems in both regular and special education is the lack of an accurate, standardized means of evaluation via which the level of a student's knowledge in each subject might be examined. A special education student should be helped in first acquiring the basic knowledge he/she lacks, and only at later stages, if possible, providing him/her with the second portion of the study program; all of this should take into account the student's abilities, the student's level of understanding and his/her age (Gabish \& Shimoni, 2006; Sharan, Shahar, \& Levine, 1998).

Special education includes a range of educational, psychological, medical and social services and approaches provided to children (and adults) defined as being disabled in the long or short term from physical, mental or emotional aspects. In addition, it operates as an appointed service that intervenes in the treatment of a child exhibiting preliminary signs of adjustment problems. The objective of preventive treatment is to anticipate treatment in order to prevent a significantly greater abnormality. The field of special education is inter-disciplinary in essence, including within it a doctor, a nurse, a social worker, a guidance counselor, a psychologist and additional supplementary elements (Bourke, 2007; Ginsburg, 2006; Heiman \& Olenik-Shemesh, 2004; Lewis, 1983; Plotnik, 2008).

The objective of special education is to rehabilitate the child with limited abilities and to prepare him/her for as normal a social and professional life as possible, to the limits of his/her abilities. Hence, one must strive to best utilize the best educational and therapeutic measures to enable the child's optimal integration into the educational framework (Cohen \& Lazer, 2004; Timor, 2004). 
Special education populations include the following groups:

a) Children with mental retardation (mild, moderate and severe);

b) Children with mental disorders (mild, moderate and severe);

c) Children with PDD (Pervasive Development Disorders);

d) Children with learning disabilities;

e) Violent children and those with behavioral disorders;

f) Children with motor and/or sensory impairment (cerebral palsy, orthopedic disabilities or physical limitations, hearing/sight impairments, chronic illnesses) (Bishara, 2005).

While the child populations in special education are very diverse, the study reported upon below refers to children learning in special education classes in standard education who can be taught specific subjects in mathematics. The use of the appropriate illustrative means can assist these children and greatly facilitate their learning.

\section{Teaching Mathematics in Special Education}

The mathematics study program in elementary education is constructed gradually, from Grade 1 to 6 . The objectives in teaching this subject are: a) acquiring concepts and structures in arithmetic and geometry; b) developing the required skills in each of the subjects (arithmetical and geometrical insights, mastering of mathematical skills, solving written problems, coping with research assignments, understanding of properties and relations between concepts, familiarity with and correct usage of mathematical language); c) preventing failures or feelings of failure, encouraging a fondness for the subject among students. For success in studying the subject, the child's functioning should be taken into account, as regards to grades and the level of his/her understanding of various mathematical and other subjects. It is important to note whether the child has failed in all subjects, only a few, or if his/her failure is focused on one subject in particular.

This knowledge should facilitate teachers in understanding the child and in identifying the source of his/her difficulties (Chen, 2007; Hotzler, Jacob, Almosni, \& Bergman, 2001; Kashti et al., 1997).

Beginning in 1920, five approaches for the teaching of mathematics have been formulated in the USA, such as: Drill and practice approach (1920-1930), focusing on the development of computational abilities through memorization; the significant teaching approach (1930-1950), developing the understanding of concepts and procedures; the new math approach (1960-1970), stressing the aspect of math's formal structure; the back to the source approach, focusing on learning control of basic skills; and the problem-solving approach (1980-1990), which attempted to develop the student's ability to describe a problem with a mathematical model that would enable its resolution. The change in mathematics teaching approaches stemmed from the lack of satisfaction in level of scholastic achievement. Findings that have arisen from international achievement tests and research literature on low achievement levels in math across the globe have raised many questions, among them, how one might integrate new educational technologies into the teaching of mathematics, and how one might stress the practical nature of mathematics (Fischbein, 1997; Geary, 2010; Ginsburg, 2009; Kashti et al., 1997; Zamir, 1998).

Success in teaching mathematics will require the definition of demands placed before the student. These demands will define the work results anticipated by the school and the student. The study program is composed of a wide number of subjects and fields of knowledge, and each subject should correspond to the student's abilities (Barkai \& Zamir, 2005).

In Israel, mathematics is considered to be one of the more important subjects being taught, taking a central place in study programs, beginning in kindergarten and right through elementary school to high school. It is also a mandatory subject for acceptance of a matriculation certificate (Eylon \& Linn, 1988; Fischbein, 1997; Ginsburg, 2009; Geary, 2010; Kashti et al., 1997; Zamir, 1998).

\section{Active Teaching of Mathematics in Special Education}

Difficulties in teaching mathematics are not a new problem, and they seem to occur with many children studying math. A lack of progress in learning may stem from many reasons, such as: lack of developmental stimuli in the child's immediate environment, low motivation to study, a child's speech impairments, slow responses and more. Therefore, in order to teach and assist children with difficulties, these factors should be taken into account during teaching, with careful consideration on how to cope with them. 
Children with difficulties require special teaching methods by which the appropriate didactic measures may be adopted to minimize the learning gap resulting from the impairments. The use of active teaching in math and the study of selected subjects in accordance with the child's ability level grant the child the ability to perform operations from memory, mechanical tasks and problem-solving. This approach also assists the child in building a positive, healthy self-image, in strengthening social processes and participation with others, and assists him/her in overcoming fear and anxiety from mathematics (Zamir, 1998).

As mentioned previously, the active teaching approach comprises five areas: humanity and socialness, student centrality, teaching program, study environment and teaching methods. Therefore, emphasis on these areas when teaching any aspect of mathematics may simplify the study materials for the student and facilitate his/her internalization and understanding; one cannot possibly teach subjects like fractions, percentages or geometric shapes without the assistance of the appropriate aids to illustrate the subject and interpret the result. The teacher should create a supportive and encouraging study environment for the student correspondent to student abilities. Stressing these areas may greatly assist the student, although it should be undertaken differentially, according to each student's individual level of abilities and fields of interest (Globman \& Harrison, 1994; Kashti et al., 1997). It should be noted that the characteristics of the active teaching approach and coping with research assignments should assist both genders in understanding the study materials and in boosting scholastic achievements (Klein, 2008).

This study examines the unique characteristics of two teaching methods-active and traditional teaching - in the teaching of mathematics in four special education classes in standard elementary education, for the purpose of evaluating the impact of teaching methods on the measure of improvement in scholastic achievement. It is reasonable to assume that the active teaching approach in teaching math in special education is more appropriate in performance and undertaking, and will obtain better results in boosting scholastic achievement (Agran \& Wehmeyer, 1999; Barkai \& Zamir, 2005; Bishara, 2005; Chen, 2007; Margalit, 2003; Montague, 2010; Reiter, 2004).

\section{Research Questions}

The research questions were as follows:

a) Will differences be found between two teaching methods—active and traditional—in mathematical achievement among special education students regarding the understanding of study materials and the ability to solve problems?

b) Will the differences in mathematical achievement among special education students correspond to their gender affiliation?

c) Is there an interaction between method and gender in relation to scholastic achievement?

\section{Study Subjects}

For research purposes, four special education classes were selected (Grades 3 and 4, students with learning disabilities).

This particular group of students was chosen because it was found compatible with the current research. None were exposed to any teaching methods so it renders the findings of the research more reliable and accurate in referring to the difference between the two teaching methods: active and traditional only. In addition, it will become possible to suggest applicable interventional programs to students at the very beginning of their school experience. Students with learning deficiencies are defined as those whose basic functioning is impaired to include: reading ability, writing, math skills in such a way that it makes it significantly difficult for that person to acquire and express knowledge at the level expected from his age group. Part of the students population with learning deficiencies are also impacted by Attention Deficit Disorder, speech, abstract thinking, language and nonverbal deficiencies (Margalit, 2003).

Two classes experienced the active teaching approach in the study of mathematics, and the other two experienced the traditional teaching approach. Each class comprised ten students, for a total study group of 40 students who were also the final sample for the research. 20 were boys (50\%) and 20 girls (50\%) the age ranged from 8 to 9 years old (average 8.3 years, standard deviation 0.45 ).

The teachers selected were similar in seniority and training in the teaching of math. In the classes experiencing the active teaching approach, an attempt was made to select teachers with similar training, who placed a 
similar emphasis on active teaching, according to the patterns of their responses to the questionnaire on characterization of teaching approaches.

The participating students were defined as special education students diagnosed with learning disabilities, studying in various elementary schools in an Arab educational framework in central Israel. From a cognitive aspect, the children's abilities were termed as normal, but they exhibited difficulties in attention spans and concentration, were easily distracted, and were slower in performing basic tasks. Regarding language, their vocabularies were meager and limited; they knew the alphabet, but had not mastered letter combinations, and had numerous spelling errors. In mathematics, they performed addition and subtraction up to 100, but experienced difficulties in multiplication and division. In addition, they exhibited difficulties in abstract thought and in verbal problem-solving. The socio-economic level of the participants was midlevel; most mothers were housewives and did not work outside the home, and the fathers earned average wages. From a social aspect, the participating students belonged to a traditional, conservative society, and, accordingly, their values, beliefs, behaviors and world views corresponded to those of their parents or the society around them.

It is worth noting that in elementary education, children are not placed in special education classes in Grade 1; only later, in Grades 2 or 3 this may occur, so as to provide each child with the opportunity to integrate into a normal class. This confirms that the basic student population evaluated regarding the two teaching approaches, active and traditional, was indeed similar, i.e. the students only entered special education classes at the time they were evaluated: they had not studied mathematics according to either of the two approaches before. The test examined the initial stages of this study arrangement, so as to evaluate their achievements in relation to the arrangement.

\section{Research Tools}

Research data was gathered via a test selected from the Ministry of Education's diverse collection of tests administrated to schools to evaluate scholastic achievements in mathematics. This test underwent preliminary testing of validation and reliability by teaching experts at schools with student populations similar to that of the research population, in settlements with similar socio-economic backgrounds. Following data gathering and evaluation of questionnaire quality, the questionnaires were adjusted and refined for research purposes. It is worth noting that class teachers were asked for their professional opinions on whether they felt the test was suited to the students in their classes, and the test questions were adapted to student levels according to teacher remarks.

The test comprised seven sections: a) addition and subtraction; b) finding the missing number; c) breaking down parentheses; d) multiplication and division; e) verbal problems; f) fractions; g) geometry. The child was asked to answer all questions in every section of the test, and relative scores for each section, as well as an overall test score were calculated. In addition, the test was administered to each child twice (on two different dates) and a difference in scores between the two tests was calculated.

The test was administered at the beginning of the year (pre) and at the end of the year (post), to evaluate the measure of improvement in each student. Two versions were used simultaneously, to avoid the repeat test effect. The children did not receive feedback following the first test undertaken.

In addition to the above, each teacher whose students participated in the research was asked to fill out a questionnaire characterizing his/her teaching approach. The objective was to determine the teaching method each teacher used-active vs. traditional-as well as what emphases in the active teaching approach were expressed in their work with the students. The questionnaire was based on Yisraeli's questionnaire (2008), adapted for the present research; it included two sections: Part A-personal background and professional variables, and Part $\mathrm{B}$-questions regarding the characterization of the teaching approach and emphasis on the various measures in the active teaching approach. This section was divided into seven areas: a) use of diverse stimuli and multi directional materials in the lesson (questions 2, 3, 4, 7, 16); b) teamwork in the classroom (questions 5,6); c) use of alternative learning, teaching and evaluative methods according to their definition (questions 9, 18, 19); d) the promotion of inter-cultural understandings and mutual dialogue (questions 14, 17); e) parental integration (question 13); f) teaching objectives-developing norms of mutual assistance and reduction of competition among students (question 11); g) teaching objectives-getting the curriculum across (question 12).

In a reliability test of internal consistency (Cronbach's alpha): for 19 questionnaire items in the questionnaire on teaching approaches, a very high reliability coefficient was obtained $(\alpha=.94)$. In addition, high reliability coefficients were obtained for the sub-scales (range of coefficients were $\alpha=.89$ to $\alpha=.85$ ). Based on the relia- 
bility coefficient, an overall score in the questionnaire on teaching approaches was calculated for each teacher via a ratings summary of all questionnaire items. The scores ranged from 18 - 72, and the higher the score, the more often the active teaching approach was used in schools over the traditional teaching approach. In addition to this, scores were calculated for the seven sub-measures.

The overall scores in the questionnaire on teaching approaches served to divide the teachers into two groups according to a median score value (median $=49$ ). The traditional teaching group included participants whose scores were lower or equal to the median score, and the active teaching group included participants whose scores were higher than the median score. The variance in overall scores on the questionnaire on teaching approaches between these sub-groups was statistically distinct $(\mathrm{t}(4)=6, p<.01)$.

\section{The Research Process}

The research was done during the 2014/2015 school year and was undertaken in four special education classes at a standard elementary education school in central Israel. The researcher visited each school separately and met with the students. Each student was asked to fill out the test questionnaire by hand, in the presence of the researcher, who was available for assistance in explanations and on the appropriate manner in which to fill out the test.

The data processing system - the research was undertaken using the quantitative method and a comparison between two repeated measures of scholastic achievement in mathematics-one measure at the beginning of the year and one measure at year's end, to evaluate the impact of the teaching approach on the change occurring in dependent variables. In other words, a personal score differential is calculated for each separate student, and a comparison is undertaken between the two groups of students based on the teaching approach.

Data analysis approach-a measure was made of the connections between independent variables (active teaching approach and traditional teaching approach, gender) and the dependent variable (progress in scholastic achievement). Two-way and three-way variance analyses were conducted with repeated time measures, as well as an examination of the correlations between the change in measures of progress in students' scholastic achievements.

\section{Findings}

\section{1) The unique pedagogic traits of the two teaching approaches}

Within the framework of the preliminary analysis, we examined the unique pedagogic traits of the two teaching approaches, active and traditional. For each of the seven sub-measures, the median values served to classify the teachers according to their level of unique traits in these teaching approaches. An examination of the distribution indicated that with four out of seven of these sub-measures, there was full congruence between teacher classification according to teaching approach and teacher classification according to median values for the sub-measures. The four sub-measures were:

a) Use of stimuli and multi-directional materials during a lesson

b) Teamwork in the class

c) Use of alternative learning and teaching methods according to their definition

d) Parental integration (according to one of Globman's \& Harrison's five measures [1994], active teaching is characterized by the emphasis on warm, interpersonal relationships among people in the school environment, and with this in mind, one can include parental integration).

For every one of these four measures, scores for teachers classified to the active teaching group were found to be higher than the measure's median, whereas scores for teachers classified to the traditional teaching group were found to be lower than the measure's median.

In the measure of inter-cultural understanding and mutual communication, the correlation was almost total, and aside from one teacher's score from the traditional teaching group, all scores were found to be higher than the median for this measure. Similarly, an almost total correlation was found in the measure of teaching objectives - conveying the study materials as planned; however, with this measure, aside from one teacher's score from the active teaching group, all scores were found to be higher than the median for this measure. Nevertheless, contrary to expectations, with the measure of teaching objectives regarding development of norms in mutual assistance and minimization of competition, no clear correlation was seen between the teacher classifications according to the two teaching approaches and the median values for this measure. The scores for one 
teacher from the active teaching group and those of all the teachers in the traditional teaching group were found to be higher than the median value for this measure.

In summary, teachers classified to the active teaching group were found to have higher scores in the use of stimuli and diverse, multi-directional materials in the lesson, in motivating teamwork, in integrating parents and in the promotion of multi-cultural understanding and mutual communication.

These teachers were found to have low scores in the measure of teaching objectives - conveying study materials as planned. Conversely, the measure of teaching objectives-developing norms in mutual assistance and minimizing competition — did not serve as an efficient means for the distinction among teachers according to the two teaching approaches.

\section{2) Differences in mathematical achievement according to teaching approach}

The research question examined whether there were differences in the level of mathematical achievement in special education from the aspect of understanding the study materials and abilities to solve problems, between two teaching approaches, active and traditional. For this purpose, a test was first administered to obtain pregrades in mathematical achievement according to teaching method. The pre-grades indicate the level of mathematical achievement before the trial year of study using the different methods. This analysis indicates that no distinct difference was found between average achievements among special education students who studied under the active teaching approach $(\mathrm{M}=79.60, \mathrm{SD}=4.26)$ and those who studied under the traditional teaching approach $(\mathrm{M}=79.95, \mathrm{SD}=5.02)(\mathrm{t}(38)=-.24, p<.05)($ Table 1$)$.

A similar analysis on post-grades following the trial year of study using the different methods revealed a distinct difference among students who studied under the two teaching approaches in levels of mathematical achievement $(\mathrm{t}(38)=4.00, p<.001)$.

Following this, a one-way variance analysis (ANCOVA) was conducted on mathematical achievement according to teaching method on post-grades, while controlling the pre-grades. In accordance with the hypothesis, this test found that in the post stage, average scholastic achievements for students studying under the active teaching approach (Est.M = 87.77, Std. Error $=.56$ ) were distinctly higher than average scholastic achievements for students studying under the traditional teaching approach $\left(\mathrm{F}(1,37)=47.50, \eta^{2}=.56, p<.001\right)(\mathrm{Est} . \mathrm{M}=$ 82.33, Std. Error $=.56$ ).

In a two-way variance analysis on teaching method and measurement time with repeated and specific time measures, a distinction was found in interaction of teaching approach and time measure $\left(F(1,38)=38.76, \eta^{2}\right.$ $=.50, p<.001$ ). Based on an analysis of pairs comparisons using the Bonferroni method, during which an adjustment was performed for multiple comparisons, it was found that the improvement in achievement levels among students studying under the active teaching approach $\left(\mathrm{F}(1,38)=163.11, \eta^{2}=.81, p<.001\right)$ was more significant than the improvement in achievement levels among students studying under the traditional teaching approach $\left(\mathrm{F}(1,37)=15.73, \eta^{2}=.29, p<.001\right)$ (Figure 1).

In response to the first research question, the findings indicate that the differences in special education students' mathematical achievements corresponded to the teaching method. It was found that with students who studied under the active teaching approach, improvement in mathematical achievement was distinctly greater than the level of mathematical achievement among students who studied under the traditional teaching approach.

At the beginning of this research, the level of achievement among students did not distinctly differ from approach to approach; however, at the end of the research, the students who studied under the active teaching approach had significantly improved their grades, to the point where this measure revealed a distinct difference in achievements between the two student groups (Table 1) (Figure 1).

\section{3) Gender differences in mathematical achievements}

The second research question examined whether the differences in mathematical achievements of special

Table 1. Averages, standard deviations and adjusted averages for mathematical achievement grades according to teaching method and measurement time.

\begin{tabular}{|c|c|c|c|c|c|c|c|c|c|}
\hline \multicolumn{5}{|c|}{ Traditional study $(\mathrm{N}=20)$} & \multicolumn{5}{|c|}{ Active study $(\mathrm{N}=20)$} \\
\hline \multicolumn{3}{|c|}{ Pre } & \multicolumn{2}{|c|}{ Post } & \multirow[b]{2}{*}{ Est.M } & \multicolumn{2}{|c|}{ Pre } & \multicolumn{2}{|c|}{ Post } \\
\hline Est.M & M & $\mathrm{SD}$ & M & $\mathrm{SD}$ & & $\mathrm{SD}$ & M & $\mathrm{SD}$ & M \\
\hline 82.33 & 79.95 & 5.02 & 82.45 & 4.62 & 87.77 & 79.60 & 4.26 & 87.65 & 3.53 \\
\hline
\end{tabular}




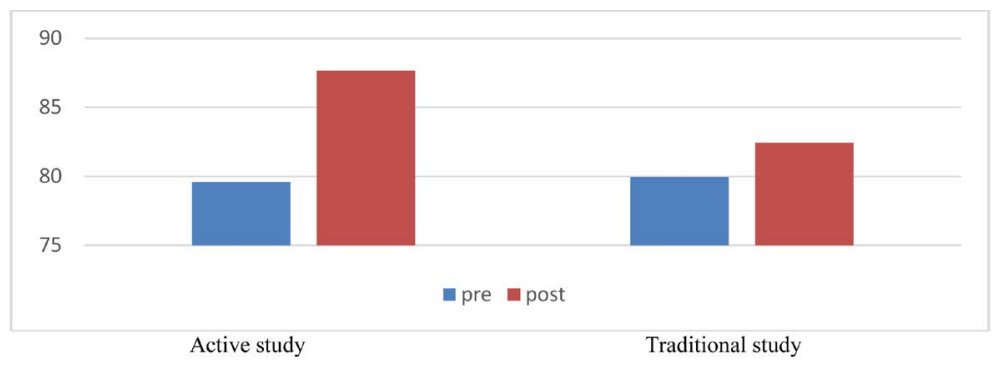

Figure 1. Mathematic achievement averages according to measurement time and teaching method.

education students corresponded to the gender affiliation of the participants. We began with a test for pregrades in mathematical achievement according to gender. An analysis of results revealed that average achievements for boys $(\mathrm{M}=83.07, \mathrm{SD}=4.38)$ were distinctly higher than average achievements for girls $(\mathrm{t}(38)=4.18$, $p<.001)(\mathrm{M}=83.07, \mathrm{SD}=4.38)$. A similar analysis conducted on post-grades revealed no distinct difference in mathematical achievement between boys and girls for this time measure $(p>.05)$.

Due to the gender differences found in the pre stage, a one-way variance analysis was conducted (ANCOVA) on mathematical achievement according to gender on post-grades, with controlled pre-grades. In accordance with the hypothesis, this test revealed that in the post stage, average achievements for girls, Est.M = 86.30, (Std. Error $=.76)$ were distinctly higher than average achievements for boys $($ Est.M $=82.96$, Std. Error $=1.03$ ) $\left(\mathrm{F}(1,37)=5.84, \eta^{2}=.14, p<.05\right)$ (Table 2$)$.

A two-way variance analysis for gender and time with repeated time measurements also revealed a distinction in interaction of gender and measurement time $\left(\mathrm{F}(1,38)=12.07, \eta^{2}=.24, p<.001\right)$. Based on an analysis of pairs comparisons using the Bonferroni method, it was found that the improvement in achievements among girls $\left(\mathrm{F}(1,38)=93.77, \eta^{2}=.171, p<.001\right)$ was greater in significance than the improvement in achievements among boys $\left(\mathrm{F}(1,38)=9.65, \eta^{2}=.20, p<.01\right)$ (Figure 2 ).

In response to the second research question, findings indicate that the change in mathematical achievements among special language students corresponded to the gender affiliation of the participants. It was found that among the girls, the improvement in mathematical achievement was distinctly greater than among the boys. At the beginning of this research, the level of achievements among the boys was distinctly higher than the level of achievements among the girls, whereas at the end of the study, the girls had significantly improved their level of achievements, until the new measure showed no distinct difference in achievement levels between the boys and the girls (Table 2) (Figure 2).

\section{4) Differences in mathematical achievement according to gender and teaching method}

The third research question examined whether there was interaction between teaching method and gender in relation to student achievement. With this purpose in mind, a three-way variance analysis was conducted, for gender, teaching method and time, with repeated time measures. No distinction was found for interaction of gender, teaching method and measurement time $(p>.05)$. Among both boys and girls, a significantly greater improvement in mathematical achievement was expressed among those who studied under the active teaching approach than for those who studied under the traditional teaching approach. Nevertheless, due to the limited scope of the sampling, this finding should be considered with caution.

In response to the third research question, findings indicate that the change in mathematical achievements among special education students according to teaching method had no correlation to their gender affiliation.

\section{Discussion and Summary}

This research had two main objectives: one-an examination of the differences between two teaching methods in teaching mathematics - active teaching and traditional teaching - in special education classes in standard elementary education, with relation to the improvement in student achievements in mathematics. The second objective was to examine the impact of gender on mathematical achievement in special education.

Three research questions were developed and empirically studied. The first question examined the differences between two teaching methods in mathematical achievement among special education students. In response to 


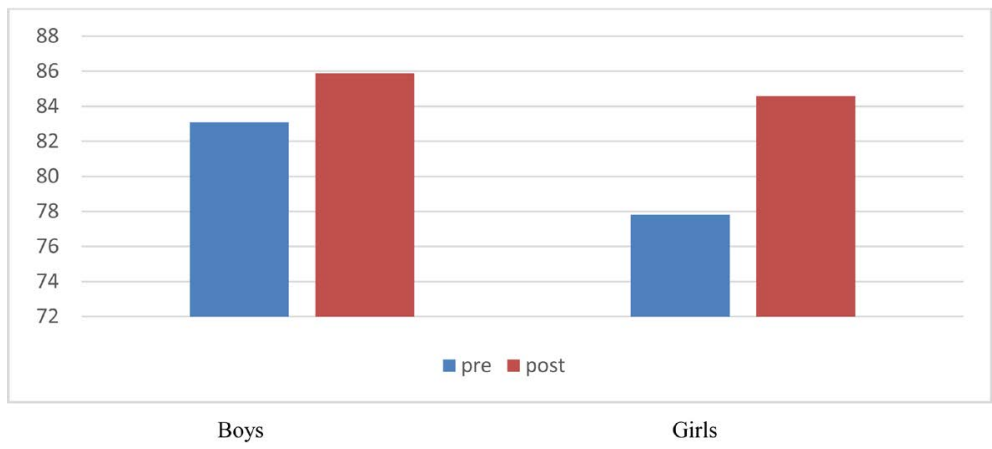

Figure 2. Mathematic achievement averages according to measurement time and gender.

Table 2. Averages, standard deviations and adjusted averages for mathematical achievement grades according to gender and measurement time.

\begin{tabular}{|c|c|c|c|c|c|c|c|c|c|}
\hline \multicolumn{5}{|c|}{ Girls $(\mathrm{N}=20)$} & \multicolumn{5}{|c|}{ Boys $(\mathrm{N}=20)$} \\
\hline \multicolumn{3}{|c|}{ Pre } & \multicolumn{2}{|c|}{ Post } & & \multicolumn{2}{|c|}{ Pre } & \multicolumn{2}{|c|}{ Post } \\
\hline Est.M & M & SD & M & SD & Est.M & SD & M & SD & M \\
\hline 86.30 & 77.80 & 3.51 & 84.56 & 5.16 & 82.96 & 83.07 & 4.38 & 85.87 & 4.27 \\
\hline
\end{tabular}

this question, findings indicated that the differences in student achievement corresponded to the teaching method; it was found that among students who studied under the active teaching approach, the improvement in mathematical achievement was significantly greater than the improvement in mathematical achievement among students who studied under the traditional teaching approach (Table 1) (Figure 1).

There is much reference to this subject in research literature, indicating that the use of active teaching methods when teaching math and other selected subjects grants the student with the ability to perform memory operations, mechanical operations and problem-solving. This approach also assists the student in building a positive and healthy self-image, and strengthens social processes and partnership with others (Zamir, 1998). The active teaching approach comprises five areas: humanity and socialness, student centrality, teaching program, study environment and teaching methods. Therefore, emphasis on these areas when teaching any aspect of mathematics may simplify the study materials for the student and facilitate his/her internalization and understanding (Kashti et al., 1997).

The use of various aspects of active learning such as: small group instruction, peer assisted learning, use of computer games, digital presentations briefs and the success of such use depends very much on the cooperation among all decision makers at school and a shared belief that this method will advance the student population by providing a unique response to each student according to his personal abilities (Yisraeli, 2008).

The second research question examined the differences in mathematical achievements among special education students with reference to their gender affiliation. Findings indicated that the differences in scholastic achievement corresponded to the gender affiliation of the participants; it was found that the improvement in mathematical achievement among girls was significantly greater than the improvement in mathematical achievement among boys (Table 2) (Figure 2).

Research literature, and in the social sciences in particular, refer to the term "gender", distinguishing between male and female, and its characteristics are dependent upon society and culture. The characteristics of the active teaching approach-humanity and socialness, student centrality, a developed teaching program, a diverse study environment and alternative teaching methods - characterize human nature, i.e. men and women together, and therefore, use of the active teaching approach should assist in understanding study materials and boost scholastic achievements among both genders (Klein, 2008). According to the other approach, the environmental, boys and girls are born with an equal mathematical intellectual potential and the gaps that exist are environmental, born of social and cultural influences through education, perceptions, expectations and conflicting messages passed on through the surrounding society, parents, teacher in general and educators in particular (Klein, 2008; Geary, 
2010).

The third research question referred to the existence of an interaction between teaching method and gender in relation to scholastic achievement. In response to this question, findings indicated that the differences in scholastic achievement among special education students according to teaching method did not correspond to the gender affiliation of the participants. It was found that for both boys and girls, the improvement in mathematical achievement was significantly greater among those who studied under the active teaching approach.

The characteristics of the active teaching approach and coping with these research assignments should assist both genders in understanding study materials and in boosting their scholastic achievements (Klein, 2008).

\section{Pedagogical Ramifications and Recommendations}

Within the framework of the present study, we have examined the link between teaching approaches—active teaching and traditional teaching-in relation to the advancement in mathematical achievements among special education students in standard elementary education. In addition, we have examined the interaction between the teaching method and gender in relation to scholastic achievement.

One of the methodological ramifications that arose during this study is that in studies examining the wide variety of teaching approaches, one must take into account the nature of the pedagogic method from the following aspects: an emphasis on social relations among classmates, an emphasis on student activity in relation to the measure of his/her personal progress and the development of flexible and diverse study materials and programs. All these should serve as efficient teaching aids in simplifying study materials for students who have learning difficulties.

In addition, from a pedagogic aspect, it is recommended to utilize the active teaching approach in schools, as this study finds that this approach may contribute to an improvement in scholastic achievements, and as a result, may have ramifications on a variety of matters related to the field of pedagogy, including: reduction of student dropout, fostering motivation to study, and improving social relationships.

\section{Research Limitations}

Due to the limitations in scope of the present study, not all of the organizational variables that might be related to the nature of the teaching approach nor additional institutional variables that might impact on scholastic achievement were examined.

The limited scope of this research was also expressed in the small sampling of students; this will necessitate a confirmation of findings in future studies conducted on larger samplings.

An additional limitation of this study is the principal method utilized, the quantitative method. The qualitative research method should also be involved, based on interviews, to enable a more in-depth and comprehensive view, for an examination of variables, teaching methods and mathematical achievements among special education students, as well as their ideological perceptions in relation to these variables.

This study might also conduct a comparison among various sectors in Israeli society which represent different socio-cultural world views. It is possible that these perceptions may project upon the concept of teaching method and scholastic achievement.

\section{References}

Agran, M., \& Wehmeyer, M. (1999). Teaching Problem Solving to Students with Mental Retardation. Innovations, 15 , 1-30.

Barkai, R., \& Zamir, P. (2005). Using Mathematics Errors: Theory and Practice. Tel Aviv: Ramot. (In Hebrew)

Bishara, S. (2005). Characteristics of the School and Improved Learning Achievements in the Areas of Basic Reading Comprehension and Mathematics of Students in Special Education in the Jewish and Arab. Ph.D. Thesis, Ramat Gan: School of Education, Bar Ilan University. (In Hebrew)

Bourke, S. (2007). Abnormalities and Prejudice: The History of Special Education in the World. Tel Aviv: YaronGulan. (In Hebrew)

Chen, D. (2007). Using Errors as a Lever for Improving Student Learning and Deepen Mathematical Knowledge. Mathematics Teachers' Bulletin, 37, 81-93. (In Hebrew)

Cohen, A., \& Lazer, I. (2004). Teachers' Attitudes toward Integration of Students by Category and Severity Exceptional Skills and Approaches for Dealing with These Students That Combines Classroom. Issues in Special Education and Rehabilitation, 19, 95-109. (In Hebrew) 
Eylon, B., \& Linn, M. C. (1988). Learning and Instruction: An Examination of Four Research Perspectives in Science Education. Review of Education Research, 58, 251-301. http://dx.doi.org/10.3102/00346543058003251

Fischbein, E. (1997). Intuition in Science and Mathematics: An Educational Approach. Dordrecht: Reidel.

Gabish, B., \& Shimoni, S. (2006). Perceptions of Teachers, including the Integration of Students with Special Needs Orientations. Issues in Special Education and Rehabilitation, 21, 35-54. (In Hebrew)

Geary, D. C. (2010). Teaching Algebra to Students with Learning Disabilities. Journal of Learning Disabilities, 46 , 31-37.

Ginsburg, H. P. (2006). Mathematics Learning Disabilities: A View from Developmental Psychology. Journal of Learning Disabilities, 40, 151-169.

Ginsburg, H. P. (2009). Mathematics Disabilities: An Underestimated Topic? Journal of Psychoeducational Assessment, 27, 171-174. http://dx.doi.org/10.1177/0734282908330577

Globman, R., \& Harrison, J. (1994). Active Learning-A Heterogeneous Approach to Teaching. In Y. Rich, \& R. Ben-Ari (Eds.), Heterogeneous Classroom Teaching Methods (pp. 55-97). Even Yehuda: Reiches. (In Hebrew)

Heiman, T., \& Olenik-Shemesh, T. (2004). Teachers Dealing with Aspects of Integrating Students with Special Needs. In G. Rozental (Ed.), Teachers in a Changing World Trends and Challenges (pp. 131-156). Ra’anana: The Open University. (In Hebrew)

Hotzler, I., Jacob, T., Almosni, I., \& Bergman, A. (2001). Guide for Integrating Children with Physical Disabilities in the School and in the Community. Tel Aviv: MOFET Institute. (In Hebrew)

Kashti, Y., Arieli, M., \& Shlansky, S. (1997). Lexicon of Education and Teaching. Tel Aviv: Ramot, Tel Aviv University. (In Hebrew)

Klein, A. (2008). It Is Heaven or Hell: Gender and Reflection in Society and Education. Tel Aviv: Kvanim. (In Hebrew)

Lewis, R. (1983). Teaching Special Student in the Mainstreaming. Columbus, OH: C. Emerriall.

Margalit, M. (2003). Resilience Model among Individuals with Learning Disabilities: Proximal and Distal Influences. Learning Disabilities Research \& Practice, 18, 82-86. http://dx.doi.org/10.1111/1540-5826.00062

Montague, M. (2010). Cognitive Strategy Instruction in Mathematics for Students with Learning Disabilities. Journal of Learning Disabilities, 46, 13-21.

Plotnik, R. (2008). Grow Differently. Holon: Yesod.

Reiter, S. (2004). Circles of Brotherhood Breaking the Link between Loneliness Limited. Haifa: Achva. (In Hebrew)

Sharan, S., Shahar, H., \& Levine, T. (1998). The Innovative School Organization and Teaching. Tel Aviv: Ramot. (In Hebrew)

Timor, Z. (2004). But Not Physical Integration Curriculum? Research Staff Perceptions of Educational Curriculum for Students with Learning Disabilities in Regular Classes Secondary School in Tel Aviv. Issues in Special Education and Rehabilitation, 19, 5-16. (In Hebrew)

Yisraeli, T. (2008). Relationship between Alternative Assessment through Research Projects, and the Motivation and Achievement in Science Education in Elementary Schools Religious State. Master's Thesis, Tel Aviv: Bar Ilan University. (In Hebrew)

Zamir, P. (1998). Affective Variables in Learning: The Case of Math Anxiety. In I. Satue, \& T. Tirosh (Eds.), Theory and Practice in Mathematics, Science and Technology (pp. 167-193). Tel Aviv: Ramot. (In Hebrew) 